\title{
TECNOCRACIA E DESPOLITIZAÇÃO DA ESFERA PÚBLICA SEGUNDO HABERMAS: ESTUDOS DE TEORIA CRÍTICA VIA RACIONALIDADE COMUNICATIVA
}

\author{
Francisco Jozivan Guedes de Lima \\ Doutor em Filosofia-PUCRS \\ Professor do PPG e do Depto Filosofia-UFPI \\ Professor do PPG Ciência Política-UFPI \\ Jozivan2008guedes@gmail.com
}

\begin{abstract}
Resumo: A pretensão deste artigo consiste em demonstrar o tratamento de Habermas acerca da racionalidade instrumental e tecnocrática e de seus impactos para a despolitização da esfera pública, tendo como ponto central a propositura do seu redimensionamento a partir da racionalidade comunicativa. Para Habermas, o projeto emancipatório da Teoria Crítica só pode ser eficaz caso se amplie a racionalidade em termos de uma ética do discurso a partir da qual as relações sejam ressignificadas para além de um direcionamento instrumental e o seu foco meramente estratégico seja reavaliado em termos de entendimento mútuo e cooperação/solidariedade.
\end{abstract}

Palavras-Chave: Esfera Pública. Racionalidade comunicativa. Racionalidade instrumental. Tecnocracia. Teoria crítica.

\section{TECHNOCRACY AND DEPOLITICIZATION OF THE PUBLIC SPHERE ACCORDING HABERMAS: STUDIES OF CRITICAL THEORY THROUGH COMMUNICATIVE RATIONALITY}

\begin{abstract}
The purpose of this article is to demonstrate Habermas' treatment of instrumental and technocratic rationality and its impacts on the depoliticization of the public sphere, having as its central point the proposition of its re-signification based on communicative rationality. For Habermas, the emancipatory project of Critical Theory can only be effective if rationality is broadened in terms of an ethics of discourse from which relations are re-signified beyond an instrumental direction and its merely strategic focus is re-evaluated in terms of mutual understanding and cooperation/solidarity.
\end{abstract}

Keywords: Public Sphere. Communicative Rationality. Instrumental Rationality. Technocracy. Critical Theory. 


\section{Introdução - A inspiração crítica em Adorno e Horkheimer}

A Teoria Crítica tem sido desde a sua primeira geração uma das correntes filosóficas contemporâneas que mais se ocupa com o tema da técnica e com seus consequentes impactos para as múltiplas esferas da vida tanto privada quanto pública. Em Dialética do Esclarecimento, Adorno e Horkheimer já estavam atentos à função da técnica no que concerne ao regresso à barbárie e à crise do projeto racionalista moderno e progressista de Aufklärung, progresso este que sucumbiu diante dos horrores e da degradação vivenciados no regime nazista. Este contexto os levou a questionar sobre o porquê da barbárie e do esvaziamento da vida.

Um dos pontos diagnosticados como responsável por tal sucumbência diz respeito a uma aporia do próprio esclarecimento que, presumivelmente racional e detentor das luzes, levou o homem moderno a uma obliteração da racionalidade emancipatória. A tese de Adorno e Horkheimer (1985, p. 13) é que houve a destruição do esclarecimento mediante o progresso técnico que transformou as massas educadas tecnicamente via indústria cultural em meros autômatos consumidores relegando a um plano ínfimo as outras esferas da vida.

A violência da sociedade industrial instalou-se nos homens de uma vez por todas. Os produtos da indústria cultural podem ter a certeza de que até mesmo os distraídos vão consumi-los de modo alertado. Cada qual é um modelo da gigantesca maquinaria econômica que, desde o início, não dá folga a ninguém, tanto no trabalho quanto no descanso, que tanto se assemelha ao trabalho. (ADORNO; HORKHEIMER, 1985, p. 105).

Desde o paradigma baconiano do experimentalismo e do instrumentalismo o homem entendeu o binômio saber-poder como dominação tanto dos homens entre si quanto da natureza. De acordo com este paradigma, cabe ao homem desvendar as leis de funcionamento da natureza para dominá-la, isto é, exercer o poder sobre ela através do conhecimento sem apelar para misticismo e metafísica, mas unicamente pela observação e pela análise dos fatos empíricos como está explícito em The New Organon (cf. BACON, 2000, p. 33).

De acordo com Horkheimer (1973, p. 103) em sua Crítica da razão instrumental publicada originalmente em 1946 no Institute of Social Research na Columbia University, este processo de domínio e instrumentalização da natureza foi consubstanciado de modo veemente, sobretudo, a partir da ideologia da sociedade industrial moderna mediante seu "aspecto niilista" imerso numa contradição que de um lado eleva e de outro condena o sujeito a uma vida precária e explorada. Isso reverberou no imperativo segundo o qual o domínio da natureza deveria ser coextensivo ao domínio do próprio homem.

A tese central de Horkheimer (1973, p. 12) posta desde o prefácio deste ensaio é a de que "o avanço dos meios técnicos se vê acompanhado por um processo de desumanização". Isso significa que a ideologia tecnocrática e a razão instrumental não cumprem um objetivo emancipatório, mas exploratório tanto do homem quanto da natureza. 
Adorno e Horkheimer (1985, p. 18) consideram que o modelo experimentalista sedimentou um positivismo e, sobretudo, instaurou um tecnicismo como um padrão de racionalidade que viria a solapar os demais padrões, inclusive os padrões de racionalidade tendentes à racionalidade discursivo-argumentativa, racionalidade esta que será o foco precípuo da perspectiva filosófico-sociológica habermasiana. Dentro do modelo da técnica o fazer amiúde irrefletido e vazio de conteúdo ético e social se interpõe como a prática par excellence instaurando, assim, o reino do homo faber e a ressignificação da própria visão de ciência. Diante desta nova tecnocracia (governo da técnica),

o que importa não é aquela satisfação que, para os homens, se chama 'verdade', mas a 'operation', o procedimento eficaz. Pois não é nos 'discursos plausíveis, capazes de proporcionar deleite, inspirar ou de impressionar de uma maneira qualquer, nem quaisquer argumentos verossímeis, mas em obrar e trabalhar e na descoberta de particularidades antes desconhecidas, para melhor prover e auxiliar a vida', que reside 'o verdadeiro objetivo e função da ciência' (ADORNO; HORKHEIMER, 1985, p. 18).

Doravante qualquer pretensão de saber que não seja submetido ao critério de calculabilidade é no mínimo suspeito e o próprio indivíduo agora destituído de subjetividade transforma-se em cômputo organizado num sistema de consumidores. Não conta mais a sua convicção política, o valor ético, a pertença cultural, o credo, mas a sua capacidade de consumo: "reduzidos a um simples material estatístico, os consumidores são distribuídos nos mapas dos institutos de pesquisa (que não se distinguem mais dos de propaganda) em grupos de rendimento assinalados por zonas, vermelhas, verdes e azuis" (ADORNO; HORKHEIMER, 1985, p. 102).

Outro ponto depreendido da Dialética do Esclarecimento é que a tecnocracia não é neutra ou imparcial; seus recursos e benesses não são globais, mas restritos a uma parcela mínima da alta sociedade que lucra com o consumismo, forjando desta forma uma casta de poderosos que ditam o modus vivendi da grande parcela dos consumidores.

Nesse sentido, no âmago da racionalidade tecnocrática está o poder e a dominação ideológica e de fato: "o que não se diz é que o terreno no qual a técnica conquista seu poder sobre a sociedade é o poder que os economicamente mais fortes exercem sobre a sociedade. A racionalidade técnica hoje é a racionalidade da própria dominação. Ela é o caráter compulsivo da sociedade alienada de si mesma" (ADORNO; HORKHEIMER, 1985, p. 100).

Dentro deste novo cenário imerso em contradições, presente de modo explícito no capitalismo, o indivíduo é mergulhado num quadro de completa irracionalidade do ponto de vista ético e político. E é justamente este cenário analisado por Adorno e Horkheimer em termos de Esclarecimento e Indústria Cultural que será ulteriormente investigado por Habermas mediante a relação entre tecnocracia e despolitização da esfera pública, dando continuidade deste modo aos intentos seminais da Teoria Crítica no tocante ao tema da racionalidade emancipatória.

Conforme destaca McCarthy (1985a, p. 176), a diferença central perante as abordagens de Adorno e Horkheimer enquanto um ponto de partida distintivo é que 
Habermas não se limitará e não ficará satisfeito com o modelo hegemônico de racionalidade instrumental dantes diagnosticado por Weber enquanto a racionalidade par excellence, algo assimilado pela Dialética do Esclarecimento. A ideia subjacente, portanto, no programa de pesquisa habermasiano consiste mormente em ampliar tal racionalidade e vinculá-la aos processos emancipatórios via racionalidade comunicativa, processos tais que passam sem sombra de dúvidas pela releitura das instituições e do Estado democrático de direito no que concerne à esfera pública.

\section{Tecnocracia, racionalidade técnico-instrumental e implicações para a esfera pública democrática}

Antes de adentrar propriamente na construção deste tópico, gostaria de destacar que intencionalmente não irei me aportar em Direito e Democracia para abordar o tema da racionalidade instrumental e de suas implicações para a esfera pública. Obviamente não estou negando a inestimável relevância dessa obra para o tema da esfera pública deliberativa, sobretudo, quando no seu sétimo capítulo Habermas (1997, p. 18) defende a política deliberativa como o âmago do processo democrático e, opondo-se ao modelo empiricista, reivindica a legitimidade do direito através de uma práxis deliberativa em vez de um modelo arraigado no mero interesse e no poder.

A sua crítica reside justamente no fato de que "a análise das condições de gênese e da legitimidade do direito concentrou-se na política legislativa, deixando em segundo plano os processos políticos." (HABERMAS, 1997, p. 9). Assim, sua tese é que a política deliberativa deve se alimentar de duas fontes: uma procedimental que diz respeito às regras do jogo democrático colocadas em pauta e viabilizadas pelo Estado democrático de direito; e outra concernente à formação democrática da vontade e da opinião, fazendo assim um entrelaçamento entre o procedimento e o conteúdo do agir democrático.

Como dito, esse horizonte jurídico de reflexão sobre facticidade e validade normativa tem sua relevância, mas a minha ideia e o meu escopo consistem em focar numa abordagem mais vinculada à razão instrumental e comunicativa, de modo que o leitor notará nestes itens subsequentes menções enfáticas à proposta habermasiana de ação comunicativa e às suas consecutivas obras que lhe servem de justificação. Direito e Democracia ser-me-á bastante útil numa outra oportunidade, numa pesquisa vindoura em que tratarei da política deliberativa.

Retomando ao ponto deste artigo, na obra habermasiana o tema da despolitização da esfera pública e sua vinculação ao tema da tecnocracia emergiu de um modo sistemático em Técnica e ciência como ideologia (1968), texto dedicado a Herbert Marcuse pelo seu septuagésimo aniversário. O ponto movedor foi 0 enfrentamento da tese de Marcuse segundo a qual a tecnologia pensada enquanto instrumentalização de coisas objetais implicaria simultaneamente na instrumentalização do homem e da natureza. Incialmente, Habermas teve a pretensão de inserir no livro em questão as Antworten auf Herbert Marcuse (Repostas a H. Marcuse), algo deixado de fora devido a sua extensão, todavia isso não impediu que a tese do homenageado ecoasse em todo o escrito.

No entender de Habermas, Marcuse depreende que a "racionalização" (Rationalisierung) weberiana tratar-se-ia não da racionalidade no seu teor mais 
ampliado, mas reconstruiria apenas uma forma de domínio técnico alavancada por uma dada classe social em específico, a saber, a burguesa, ocorrendo a partir daí uma fusão entre tecnologia e dominação, entre racionalidade técnico-instrumental e opressão. A leitura de Marcuse (1991, p. 148) em One-Dimensional Man é que

na realidade social, apesar de todas as mudanças, a dominação do homem pelo homem ainda é o continuum histórico que liga razão pré-tecnológica e tecnológica. Todavia, a sociedade que projeta e realiza a transformação tecnológica da natureza altera a base da dominação ao substituir gradualmente dependência pessoal (do escravo ao senhor, do servo ao senhor do feudo etc.) por dependência da 'ordem objetiva das coisas' (leis de mercado etc.).

A técnica não emancipou os homens, mas os tornou ainda mais dependentes, além de todo um conjunto de perdas imposto à natureza, devido os meios de exploração cada vez mais refinados e ao mesmo tempo agressivos capazes de destruir ecossistemas dantes resguardados. Além disso, a base de dominação e exploração ganhou proporções cada vez mais global no sentido que despersonalizou o poder de um homem sobre o outro e o ressignificou em termos de subjugação a um sistema; junto com a pseudo globalização do mercado adveio a globalização da dominação sistêmica da tecnocracia.

Mesmo se detendo na crítica da unidimensionalidade da racionalidade tecnocrática, Marcuse deu esteio para a abordagem de um novo tipo de racionalidade que viesse a colocar em relevo a necessidade de um redimensionamento da racionalidade para além do viés tecnocrático; a sua mensagem precípua no entender de Habermas é que "ao invés de tratarmos a natureza como um objeto de possível disposição técnica, poderíamos nos relacionar com ela como parceiros de uma possível interação. Ao invés de explorada, poderíamos buscar uma natureza fraterna" (HABERMAS, 2014a, p. 84).

O que está em jogo é a tentativa de elevar a racionalidade técnicoinstrumental para além das pretensões reificantes, um desafio que se interpôs desde o seu início como uma conditio sine qua non para o êxito do programa emancipatório da Teoria Crítica como pontuado acima na introdução deste artigo.

Habermas, semelhantemente a Marcuse, também avalia que a "racionalização" weberiana designa tão-somente - e talvez foi simplesmente apenas este 0 intuito de Weber - uma especificidade de atividade econômica capitalista. Apesar de Weber (1944, p. 20) ter intuído em Wirtschaft und Gesellschaft (1922) um conceito de "ação social" que perpassasse a (i) racionalidade teleológica com respeito a fins, (ii) racionalidade com respeito a valores, (iii) ação social afetiva ou emotiva, (iv) ação tradicional baseada nos costumes, mesmo assim o ponto prevalecente em sua teoria fora o primeiro, isto é, o da racionalidade técnicoinstrumental-teleológica reduzindo a ação a uma relação de meio-fim, a dita "Zweckrationalität". Dentro de tal recorte estariam vislumbradas apenas as relações do direito privado, a reconstrução histórica do espírito e da cultura capitalista e a dominação burocrática, um tipo de análise relevante, porém restritiva em termos de racionalidade no sentido ampliado.

No entender de Habermas, a consciência tecnocrática caracteriza-se por não velar sua ideologia, mas por disponibilizá-la abertamente e pelo poder de sedução 
ou mesmo de coerção dos indivíduos implementando inclusive uma indústria cultural de consumo como possibilitação de venda de seus produtos. Neste sentido, a tecnocracia enquanto uma ideologia instrumental e de poder que sedimenta e retroalimenta o capitalismo tornou-se forte a ponto de possivelmente levar o conceito marxiano de "luta de classes" à sua latência na medida em que consegue a adesão das massas proletárias em troca da promessa de qualidade de vida.

O capitalismo regulado pelo Estado, que surge como reação aos perigos que o antagonismo aberto de classes representava ao sistema, promove o abrandamento dos conflitos de classes. $O$ sistema de capitalismo tardio é de tal modo definido por uma política compensatória que assegura a lealdade das massas assalariadas (ou seja, por uma política de supressão do conflito), que o conflito próprio da valorização privada do capital, inscrito como antes na estrutura da sociedade, possui maior probabilidade de permanecer latente (HABERMAS, 2014a, p. 112).

Habermas defende a conjectura que, sobretudo, a partir do fim do século XIX, o desenvolvimento do capitalismo impulsionado pela racionalidade instrumental e teleológica caracterizou-se marcadamente por uma busca de cientificização da técnica tirando-a da mera rudimentação, operacionalizando-se assim o recurso em termos administrativos à burocracia enquanto processo de racionalização.

Seguindo o diagnóstico da sociologia política de Claus Offe e seu diagnóstico da eliminação dos conteúdos práticos da esfera pública com as questões éticas concernentes à vida boa etc., depreende que o capitalismo estatalmente regulado e protegido ocasionou uma "despolitização das massas populares" e em termos amplos uma "despolitização da esfera pública". "A nova política do intervencionismo estatal requer uma despolitização das massas populares. Com a eliminação de questões práticas, a esfera pública política perde também sua função" (HABERMAS, 2014a, p. 112).

A ideologia tecnocrática fez-se presente de modo forte nos subsistemas econômico (capitalismo) e administrativo (Estado) e estendeu seu modus vivendi e seus padrões instrumentais de racionalidade ao Lebenswelt.

O sistema econômico troca o salário por trabalho (como input específico), assim como bens e serviços (como output de produtos próprios) pela demanda dos consumidores. A administração pública permuta realizações organizatórias por impostos (como input específico) e decisões políticas (como output de produtos próprios) pela lealdade das massas (HABERMAS, 2012a, p. 577).

O parecer de Habermas é que tal colonização implicou a burocratização e monetarização da vida tanto privada quanto pública no sentido da sua reverberação no espaço comum, de modo que as possíveis dinâmicas sociais de solidariedade foram paulatinamente solapadas. A isso ele chama de "unilateralização dos estilos de vida"; nela ocorrem a potencialização e a dominação de apenas um tipo de racionalidade, o da racionalidade instrumental que implica o estilo de vida segundo 0 
qual vínculos éticos são arrefecidos e suplantados por laços de interesses egocêntricos.

\begin{abstract}
À medida que o sistema econômico submete a seus imperativos a forma de vida das economias domésticas privadas e a conduta de vida de consumidores e assalariados, o consumismo e 0 individualismo possessivo, bem como os motivos relacionados com o rendimento e a competitividade, se transformam na força configuradora. A prática comunicativa cotidiana é racionalizada unilateralmente a favor de um estilo marcado pela especialização e pelo utilitarismo; e tal mudança para orientações da ação racionalteleológicas, induzidas pelos meios, provoca a reação de um hedonismo que tenta aliviar essa pressão oriunda da racionalidade. Do mesmo modo que o sistema econômico solapa a esfera privada, a esfera pública é esvaziada pelo sistema administrativo (HABERMAS, 2012a, p. 587-588).
\end{abstract}

A despolitização na esfera pública foi consumada com a tecnicização da política tomando por base a relação entre saber especializado e práxis política implementada em termos de um modelo decisionista. Segundo tal modelo, a função do povo consiste tão-somente em endossar o poder de uma determinada elite política mediante a função do voto e as decisões mais consubstanciais concernentes à vida pública são intencionalmente marginalizadas ou mesmo indiferentes. Neste aspecto, o processo de formação da vontade democrática desfalece e perde sua razão de ser já que as decisões são forjadas por determinadas autoridades (auctoritas non veritas facit legem).

\begin{abstract}
Se a divisão de competências entre os especialistas e os líderes de fato se estabelece do modo como defende o modelo decisionista, a esfera pública política constituída pelo público de cidadãos pode servir apenas para a legitimação dos grupos líderes. [...] as votações se referem apenas ao preenchimento das posições de autoridade decisória (HABERMAS, 2014a, p. 159).
\end{abstract}

Esta elitização dos processos decisórios dos temas da política esvazia a esfera pública ou a transforma simplesmente numa "esfera pública burguesa" onde as decisões são tomadas aristocraticamente por uma classe de poder seja ela política ou político-empresarial sob o aval - mesmo que conscientemente não consentido do povo via instrumentalização do voto. Todavia, desde Strukturwandel der Öffentlichkeit (1962), Habermas já advertia que "a esfera pública burguesa se rege e cai com o princípio do acesso a todos. Uma esfera pública, da qual certos grupos fossem eo ipso excluídos, não é apenas, digamos incompleta: muito mais além, ela nem sequer é uma esfera pública" (HABERMAS, 2003, p. 105).

Em Im Sog der Tecnokratie (2013), Habermas continua com o mesmo fôlego crítico ao se opor à redutibilidade da esfera pública ao aparato tecnocrático da lógica sistêmica de manutenção do capital quando salienta a necessidade de a democracia deliberativa romper com a instrumentalização do voto e, neste sentido, apontando para a repolitização da esfera pública: 
[...] uma abordagem apoiada na teoria da comunicação pode reservar uma certa plausibilidade para a promessa democrática da inclusão, portanto, para a participação de todos os cidadãos no processo político. Não nos cabe reduzir eleições e referendos ao ato do voto. Esses votos alcançam o peso institucional das decisões dos colegisladores somente em vínculo com uma esfera pública vital, isto é, com a dinâmica dos prós e contras de opiniões, argumentos e tomadas de posição flutuando livremente. Eleições políticas são algo diferente de sondagens demoscópicas; elas não devem apenas reproduzir um espectro de preferências existentes. [...] temos de nos despedir de uma imagem institucionalmente congelada do Estado democrático de direito (HABERMAS, 2014b, p. 98).

Habermas critica a formação da União Europeia tributária no seu entendimento de elites políticas sustentadas sob o assentimento passivo do povo e ancoradas na promessa de vantagens econômicas, o que caracteriza uma política de resultados, portanto, meramente teleológica e instrumental; "a União se legitimou aos olhos dos cidadãos, sobretudo, por seus resultados, e não tanto pela satisfação de uma vontade civil política" (HABERMAS, 2014b, p. 117).

Ao tratar da relação entre democracia e capitalismo sob a intitulação "da miséria de uma sociedade mundial fragmentada pelos Estados nacionais e integrada pelo capitalismo", Habermas conjectura que pensar a União Europeia sob a perspectiva economicista de União monetária implica transformar o Estado democrático num Estado de impostos e consequentemente num Estado de dívidas (HABERMAS, 2014b, p. 185).

Este modelo é, segundo os três modelos normativos de democracia postos em $A$ inclusão do Outro, a saber, o liberalismo, o republicanismo e o deliberativo, um modelo simplesmente liberal de matriz economicista onde o Estado é pensado como mero aparato da administração pública e a sociedade como um sistema de pessoas regido segundo leis de mercado onde prevalece o homo oeconomicus (HABERMAS, 2012b, p. 270).

Trata-se, portanto, reportando-se à Rechtsphilosophie (1820) de Hegel de um paradigma centrado na sociedade civil burguesa pautado no sistema de carecimento (Bedürfnis), onde o bourgeois se sobrepõe ao citoyen e "os indivíduos são, enquanto cidadãos desses Estados, pessoas privadas, as quais têm por fim seu interesse próprio" (HEGEL, 2010, § 187).

A tese de Habermas é que a esfera pública só se constrói sobre a plataforma de um Estado democrático de direito cujos indivíduos não são atomizados, mas compromissados com a vida coletiva em suas relações e, destarte, a autonomia ${ }^{1}$ é vivenciada em termos de autonomia política em que o cidadão percebe-se como colegislador, autor e destinatário das normas que regem o espaço público; com isso

\footnotetext{
${ }^{1}$ A partir de uma proposta moral pós-kantiana, Habermas nos Comentários à ética do discurso diz que a ética do discurso abandona o conceito de autonomia oriundo da filosofia da consciência e ancora-se num conceito intersubjetivista de autonomia que leva em consideração a prerrogativa que o desenvolvimento da personalidade individual só é possível a partir da realização da liberdade de todos os indivíduos. Isso implica que não há autonomia no isolamento. (cf. HABERMAS, 1999, p. 27).
} 
instaura-se uma vinculação normativa entre Estado de direito e democracia deliberativa.

Uma ordem jurídica é legítima quando assegura por igual a autonomia de todos os cidadãos. E os cidadãos só são autônomos quando os destinatários do direito podem ao mesmo tempo entenderse a si mesmos como autores do direito. $E$ tais autores só são livres enquanto participantes de processos legislativos regrados de tal maneira e cumpridos sob tais formas de comunicação que todos possam supor regras firmadas desse modo mereçam concordância geral e motivada pela razão. Do ponto de vista normativo, não há Estado de direito sem democracia (HABERMAS, 2002a, p. 242-243).

\section{O redimensionamento da racionalidade tecnocrática: a proposta de racionalidade comunicativa}

Como premissa basilar de sua teoria discursiva, Habermas (2002c, p. 205) distingue dois tipos de ação comunicativa, uma no sentido fraco onde a linguagem é usada para a expressão da vontade unilateral dos indivíduos e declaração de práticas usuais do cotidiano, e outra no sentido forte onde a linguagem é acessada como medium para o entendimento mútuo e, ipso facto, para a vinculação intersubjetiva das vontades superando desta forma o polo solipsista das preferências pessoais.

$\mathrm{Na}$ ação comunicativa fraca os agentes são orientados apenas para as pretensões de verdade e sinceridade, enquanto que na ação comunicativa forte o são também para as pretensões de correção intersubjetivamente reconhecidas. No caso da ação comunicativa forte, é não só a liberdade de escolha arbitrária que é pressuposta, mas também a autonomia, no sentido de união de vontades com base em discernimentos normativos.

$\mathrm{Na}$ ação comunicativa forte as interações sociais são orientadas para a concordância; na ação comunicativa fraca as ações são estratégicas e visam as consequências e resultados da ação. A racionalidade tecnocrática pauta-se numa ação comunicativa no sentido fraco.

Indo além de Marcuse, Habermas não se limita a repudiar ${ }^{2}$ a racionalidade tecnocrática haja vista esta ser um dado prima facie inescapável, no sentido que a capacidade de governo do poderio técnico colonizou todas as esferas da vida e trouxe junto consigo o experimentalismo e instrumentalismo como a marca do seu modo de legitimação nas sociedades capitalistas consumistas.

Em vez disso, Habermas tenciona redimensioná-la a partir da propositura de um outro tipo ou padrão de racionalidade: a comunicativa - daí todo o seu esforço

\footnotetext{
2 De acordo com McCarthy (1985b, p. 22), "o problema real, argumenta Habermas, não é a razão técnica enquanto tal, mas a sua universalização, o confisco de uma concepção de razão mais abrangente em favor da validade exclusiva do pensamento científico e tecnológico, a redução da práxis à techne $[\ldots] "$.
} 
em subsidiar filosófico e interdisciplinarmente a ética do discurso (Ethik der Rede, Diskursethik), inicialmente trabalhada em parceria com Karl-Otto Apel e depois levada a cabo meio que solitariamente em virtude de o projeto apeliano se voltar para uma perspectiva fundacionista da busca da Letztbegründung (fundamentação última). ${ }^{3}$

É necessário frisar que Habermas se afasta da proposta de Apel justamente devido a esta dependência e conotação metafísica em termos de fundamentação última, algo não suportável dentro de contextos pós-seculares hodiernos que demandam justificações pós-metafísicas. Destarte, Habermas faz uma opção pela pragmática universal entendida como um método reconstrutivo que tenciona "identificar e reconstruir condições universais de possível compreensão mútua (Verständigung)" (HABERMAS, 1998, p. 21).

A tentativa habermasiana em redimensionar a racionalidade tecnocrática é feita a partir da sua distinção entre ação comunicativa e ação instrumental:

\begin{abstract}
O agir comunicativo distingue-se, pois, do estratégico, uma vez que a coordenação bem-sucedida da ação não está apoiada na racionalidade teleológica dos planos individuais de ação, mas na força racionalmente motivadora de atos de entendimento, portanto, numa racionalidade que se manifesta nas condições requeridas para um acordo obtido comunicativamente (HABERMAS, 1990, p. 72).
\end{abstract}

A ação comunicativa se interpõe como distinta da "ação social"4 weberiana à medida que considera o ponto de partida da intersubjetividade e dos processos de socialização dos agentes do discurso como condição imprescindível no emolduramento da normatividade; de fato o próprio Weber (2002, p. 22) parece se dar conta da sua focagem monológica da "ação social" quando ele mesmo afirma que "a 'ação' no sentido da orientação subjetivamente inteligível da conduta existe somente como a conduta de uma ou mais pessoas individuais." Tal enfoque é duramente rebatido, pois no prisma da Teoria Crítica, implica uma ação monológica.

Em termos honnethianos de The Fabric of Justice, apenas para ilustrar um breve exemplo, isso apenas conduz a uma "patologia social". A filosofia social e política hodierna e as teorias da justiça devem dar-se conta que a subjetividade e a autonomia só se constroem nas relações sociais: "nós não adquirimos autonomia por nós mesmos, mas apenas em relação com as outras pessoas que estão

\footnotetext{
${ }^{3}$ De acordo com Gerhard Schweppenhäuser, Habermas teria se antecipado a Apel nas formulações básicas da ética do discurso em 1969 num evento no Deutscher Kongress für Philosophie em Düsseldorf contrapondo-se a uma fundamentação subjetivista da ética. Foi a partir disso que Habermas imprimiu a sua marca na filosofia, a saber, a consideração intersubjetiva acerca do transcendental redimensionando-o a partir de uma focagem linguístico-pragmática. (cf. SCHWEPPENHÄUSER, 1989, p. 122).

${ }^{4}$ De acordo com Andrew Edgar (2006, p. 3), Habermas segue a sociologia de Max Weber no entendimento do conceito de "ação" quando este faz uma distinção entre ação e comportamento: ação é um ato consciente com vistas a levar outrem a uma reação; ela é performativa. $O$ comportamento é um ato involuntário ou casual movido por estímulos externos. O plus de Habermas está na adição do designativo "social" para evidenciar que toda ação é social porque envolve compreensão mútua, e a linguagem que se interpõe como medium desta compreensão é uma esfera de natureza eminentemente intersubjetiva.
} 
dispostas a estimar-nos e que temos de ser capazes a estimá-las" (HONNETH, 2015, p. 165). Em outros termos, o self configura-se apenas no engajamento e, ipso facto, para além de todas as premissas abstrativas e monológicas.

A ação comunicativa no interior da ética do discurso constitui uma alternativa ao modelo tecnocrático da ação instrumental no sentido que toma o outro não como o oponente (Gegner) a ser dobrado, mas como parceiro (Partner) do discurso. A linguagem constitui para Habermas um horizonte intersubjetivo capaz de conduzir os agentes ao entendimento mútuo e, por isso, não é apenas um mero instrumento de comunicação ou um flatus vocis.

Como destaca Georgia Warnke (1995, p. 120), a racionalidade comunicativa começa a ser reconstruída por Habermas a partir da questão de como a linguagem tem a habilidade de coordenar a ação de modo consensual tendo em vista a cooperação em oposição a um modo forçado ou manipulado. Ou seja, a questão central subjacente é como a linguagem pode conduzir a processos de compreensão mútua superando destarte os limites do subjetivismo. A linguagem ocupa assim uma função pragmática sob o pressuposto de uma razão destranscendentalizada.

Em termos da teoria dos atos de fala de Austin e Searle ${ }^{5}$ - recepcionada por Habermas na sua Teoria do Agir Comunicativo -, a ação comunicativa remete aos "atos ilocucionários", isto é, aqueles atos que têm uma pretensão normativa (dizem respeito a regras e promessas) e são performativos, conduzem a uma ação, enquanto que a ação instrumental diz respeito aos "atos perlocucionários", correspondem à persuasão e à influenciação do oponente. Os "locucionários" são meramente constatativos e dizem respeito ao simples ato de pronunciar um enunciado (HABERMAS, 2012a, p. 565).

$\mathrm{Na}$ ação comunicativa "os participantes da interação unem-se através da validade pretendida de suas ações de fala ou também em consideração aos dissensos constatados. Através das ações de fala são levantadas pretensões de validade criticáveis, as quais apontam para um reconhecimento intersubjetivo" (HABERMAS, 1990, p. 72). A ação comunicativa enquanto uma alternativa ao esvaziamento de conteúdos políticos produzido pelo modelo tecnocrático revitaliza a esfera pública em direção à sua repolitização na medida em que é capaz de acolher a multiplicidade de intervenções onde o foco é o consenso, porém sem impedir os dissensos. Neste sentido, é equivocada a crítica de Marcelo Neves (2001, p. 126) quando afirma que Habermas sobrecarregou o mundo-da-vida com pretensões consensualistas em detrimento do dissenso.

Em termos de "racionalização", a ação comunicativa tem como foco precípuo a emancipação, individuação e expansão da comunicação livre de dominação, enquanto a racionalidade tecnocrática tenciona o aumento das forças produtivas e a expansão do poder da técnica (HABERMAS, 2014a, p. 92). Uma vincula-se à revitalização da cidadania em termos de uma democracia deliberativa, a outra concerne à qualificação dos indivíduos para a retroalimentação do mercado.

A preocupação fundamental de Habermas centra-se justamente em torno do risco de se ver colapsar de vez a esfera da prática social discursiva e o engradecimento e absolutização da esfera da técnica, o que daria razão a Marcuse no seu diagnóstico da tese da unidimensionalidade e o consequente primado da

5 O cerne da teoria dos atos de fala é expresso nos seguintes termos: "falar é executar atos de acordo com certas regras" (SEARLE 1981, p. 33). 
tecnocracia enquanto mantenedora do capitalismo e da civilização industrial em detrimento da Crítica pensada aqui em seus termos sociais e políticos. Nesta direção, Habermas, mediante as categorias "Arbeit" (trabalho) e "Interaktion" (interação), propõe um redimensionamento categorial com vistas à reformulação da Rationalisierung para além do enfoque subjetivo weberiano e perpetuado por Parsons:

Por 'trabalho' ou ação racional com respeito a fins entendo a ação instrumental ou a escolha racional, ou ainda uma combinação entre ambas. A ação instrumental é regida por regras técnicas baseadas em conhecimentos empíricos. [...]. Por ação comunicativa eu entendo, por outro lado, uma interação simbolicamente mediada. Ela se orienta por normas obrigatoriamente válidas, as quais definem expectativas recíprocas de comportamento e devem ser compreendidas e reconhecidas por pelo menos dois agentes (HABERMAS, 2014a, p. 91).

Em Agir comunicativo e razão destranscendentalizada (2002b, p. 67), Habermas propõe quatro critérios discursivos com vistas ao êxito da racionalidade comunicativa:

(a) Publicidade e inclusão: ninguém que, à vista de uma exigência de validez controversa, possa trazer uma contribuição relevante, deve ser excluído; (b) direitos comunicativos iguais: a todos são dadas as mesmas chances de se expressar sobre as coisas; (c) exclusão de enganos e ilusões: os participantes devem pretender o que dizem; e (d) não-coação: a comunicação deve estar livre de restrições que impedem que o melhor argumento venha à tona e determine a saída da discussão.

Habermas (1998, p. 23) entende que o acordo entre os agentes morais dispostos a estabelecer uma pretensão de validade universal de suas propostas deve ter por base quatro pilares: compreensibilidade, verdade, sinceridade e justiça. Sem tais pressupostos as relações privadas e públicas em nível de Öffentlichkeit ficarão abandonadas aos intentos meramente instrumentais da concorrência e da imposição de cosmovisões provocando conflitos e violência.

O que deve valer dentro de um modelo de ação comunicativa não é o melhor marketing ou a melhor propaganda, mas o argumento mais consistente do ponto de vista do respeito aos princípios democráticos do Estado de direito. ${ }^{6}$ É nesse sentido que, de acordo com Forst (2010, p. 235), a fundamentação normativa em Habermas ocorre sob a perspectiva do melhor argumento: "normas válidas devem merecer o reconhecimento por parte de todos os concernidos: portanto elas devem satisfazer o

\footnotetext{
${ }^{6}$ De acordo com Martin Sell (1991, p. 47) a ação comunicativa habermasiana pressupõe que elevemos a nossa capacidade de justificar publicamente nossas pretensões de validade. Nesse sentido, podemos afirmar que esta necessidade de justificação pública de nossas pretensões torna a racionalidade comunicativa um tipo de razão apropriada ao modelo democrático.
} 
princípio de universalização $(U)$ introduzido como uma regra de argumentação para discursos morais."

No mundo tomado apenas em sentido tecnocrático onde as relações são mediadas apenas de modo instrumental (meio-fim), as relações são superficiais, movediças e cada vez mais positivadas por códigos em vez de laços éticos de respeito e confiabilidade mútuos; e consequentemente, bem como Habermas aponta em Linguagem e Comunicação (2002c, p. 205), a própria linguagem torna-se apenas um assessório de convencimento e imposição, tratando-se, desta forma, uma linguagem orientada para as consequências e para os resultados, algo que se poderia denominar de apropriação teleológica da linguagem onde os fins passam a justificar os meios.

Além de superar os limites da racionalidade instrumental, a teoria do discurso supera os limites do positivismo jurídico e do direito natural no sentido: diferentemente do positivismo jurídico que depreende suas normas a partir de uma regra arbitrária que se tornou hábito, e diferente do direito natural que supõe leis incondicionadas apoiadas em pretensões metafísicas genéricas e inconsistentes diante do pluralismo contemporâneo, a teoria do discurso tem sempre diante de si a pretensão de construir normas democraticamente válidas, deliberadas e endossadas pelos agentes normativos concernidos em questão.

Portanto, "a fonte normativa da legitimidade brota, segundo essa concepção, da combinação da inclusão de todos os concernidos e do caráter deliberativo de formação da sua opinião e da sua vontade" (HABERMAS, 2014b, p. 100).

Com isso projeta-se normativamente, ao menos em nível procedimental, uma repolitização da esfera pública onde a política transita do simples burocratismo e elitismo, deixa de ser operacionalizada pelo modelo decisionista de uma parcela de técnicos, especialistas e de alguns grupos de poder, e horizontaliza-se em práticas de simetria discursiva com vistas à emancipação em vez da dominação e imposição de um dado status quo. "Esse estabelecimento da vontade política horizontal, voltada ao entendimento mútuo ou ao consenso almejado pela via comunicativa, deve gozar até mesmo de primazia, se considerado do ponto de vista genético quanto normativo" (HABERMAS, 2002b, p. 270).

\section{Considerações finais}

O resultado depreendido neste artigo é o de que a esfera pública democrática só pode ser reabilitada mediante uma ação comunicativa forte que redimensione a racionalidade instrumental mantenedora da tecnocracia para além de uma relação meio-fim onde as ações são estratégicas em vez de éticas.

Outro ponto depreendido é que tomando por base a proposta habermasiana é plausível demarcar a seguinte fronteira entre dois espectros de ação social: o da ação comunicativa no qual os agentes éticos devem orientar suas relações intersubjetivas para o entendimento mútuo e para os processos emancipatórios; e o da ação instrumental onde os indivíduos atomizados usam da razão para perseguir seus objetivos com foco em resultados e, nisso, o outro não é tomado como Partner (parceiro) mas como Gegner (oponente).

Este tipo de racionalidade instrumental legitimada dentro da própria filosofia e da ciência moderna reverberou dentro do próprio domínio do político e, no parecer 
de Habermas, afetou as bases sociais democráticas do Estado de direito, especificamente, mediante a colonização do ethos do Lebenswelt pelo poder e pelo dinheiro. Isso implicou o fortalecimento da ideologia tecnocrática, de modo que o governo e poder da técnica pulverizou-se em várias dimensões da vida humana, tornando o homem cada vez mais dependente e subserviente a tal ideologia, recaindo numa unidimensionalidade e empobrecimento das demais esferas da existência.

Se de um lado a racionalidade em seu viés instrumental - à medida que estimula indivíduos egoístas e autointeressados - solapa as bases intersubjetivas da democracia, de outro lado, a racionalidade em seu prisma comunicativo preenche a base societária demandada pelos procedimentos democráticos por meio da interação entre os sujeitos, de modo que no primeiro espectro a esfera pública é corroída e redutível ao âmbito do privado, enquanto que no segundo é restaurada e repolitizada.

Nesse sentido, é plausível afirmar que o remodelamento da democracia em crise em nível global, não é um problema de realismo político e de mediação de conflitos de interesse, mas um problema concernente aos padrões de racionalidade que perpassam as dimensões estruturais nas múltiplas esferas da vida (política, economia, cultura, sociedade, administração). A esfera pública não pode ser refuncionalizada em termos de solidariedade, emancipação e solidariedade enquanto imperar em nós e nas instituições a racionalidade instrumental que torna a razão apenas um medium para lograr vantagens pessoais por meio da articulação meios-fins.

A contribuição precípua da teoria crítica e da ética discursiva habermasianas consiste, mormente, em demonstrar e justificar filosoficamente a necessidade de ampliação (Erweiterung) da racionalidade para além dos seus limites meramente instrumentais: a ação social não pode ser praticada somente tendo em vista meiofim/consequências-resultados.

Com isso, Habermas mostra que a crítica da primeira geração da Escola de Frankfurt à Aufklärung e ao progresso da razão moderna que definhou e chegou à sua sucumbência no século XX, especialmente com a Segunda Guerra Mundial, tem sua razão de ser enquanto crítica a um tipo específico de racionalidade, a instrumental, porém não tem seu sentido de ser como crítica à racionalidade comunicativa que quebra os binômios meio-fim/consequências-resultados.

A racionalidade instrumental sedimentou a tecnocracia e isso reverberou em nível de impacto na esfera pública no que concerne ao esvaziamento dos conceitos políticos, tornando as relações mediadas, sobretudo, por métricas economicistas e, ipso facto, o Estado perdeu paulatinamente seu poder de coesão social por meio da participação cidadã nos processos deliberativos, já que estes cidadãos foram transformados em meros consumidores.

Diante deste cenário tecnocrático as relações éticas foram suplantadas por relações concorrenciais que se pulverizaram em múltiplas esferas da vida. Este quadro pode ser traduzido em termos de uma predominância do modelo neoliberal da autovantagem em detrimento da democracia pensada em seu sentido mais radical enquanto modelo baseado na cooperação e na solidariedade.

Portanto, a partir de Habermas pode-se pensar que a repolitização da esfera pública e o resgate dos valores democráticos da cooperação e da solidariedade 
apenas são possíveis mediante o redimensionamento da própria racionalidade que, como sustentado ao longo deste artigo, deve ser repensada no segmento de uma ação comunicativa orientada ao entendimento mútuo e à emancipação.

Sem esta guinada a hegemonia da técnica continuará obliterando a potencialização da esfera pública democrática, a esfera econômica continuará a impor o seu status quo, e a solidariedade pensada enquanto valor ético-político basilar será cada vez mais arrefecida e solapada e as relações humanas continuarão atomizadas e fundadas na métrica do autointeresse e da autovantagem.

\section{REFERÊNCIAS:}

ADORNO, Theodor; HORKHEIMER, Max. Dialética do Esclarecimento: fragmentos filosóficos. Trad. Guido de Almeida. Rio de Janeiro: Zahar, 1985.

BACON, Francis. The New Organon. Edited by Lisa Jardine; Michael Silverthorne. New York: Cambridge university Press, 2000.

EDGAR, Andrew. Habermas: The Key Concepts. New York: Routledge, 2006.

FORST, Rainer. Contextos da justiça: Filosofia política para além de liberalismo e comunitarismo. Trad. Denilson Luís Werle. São Paulo: Boitempo, 2010.

HABERMAS, Jürgen. Técnica e ciência como 'ideologia'. Trad. Felipe Gonçalves Silva. São Paulo: Editora Unesp, 2014a.

HABERMAS, Jürgen. Na esteira da tecnocracia: pequenos escritos políticos XII. Trad. Luiz Repa. São Paulo: Editora Unesp, 2014b.

HABERMAS, Jürgen. Teoria do agir comunicativo, 2: sobre a crítica da razão funcionalista. Trad. Paulo A. Soethe. Revisão de Flávio Beno Siebeneichler. São Paulo: Editora WMF Martins Fontes, 2012a.

HABERMAS, Jürgen. Teoria do agir comunicativo, 1: racionalização da ação e racionalização social. Trad. Paulo A. Soethe. Revisão de Flávio Beno Siebeneichler. São Paulo: Editora WMF Martins Fontes, 2012b.

HABERMAS, Jürgen. Mudança estrutural da esfera pública: Investigações quanto a uma categoria da sociedade burguesa. Trad. Flávio Kothe. Rio de Janeiro: Tempo Brasileiro, 2003.

HABERMAS, Jürgen. A inclusão do outro: estudos de teoria política. Trad. George Sperber e Paulo Soethe. São Paulo: Loyola, 2002a.

HABERMAS, Jürgen. Agir comunicativo e razão destranscendentalizada. Trad. Lucia Aragão. Rio de Janeiro: Tempo Brasileiro, 2002b.

HABERMAS, Jürgen. Racionalidade e comunicação. Trad. Paulo Rodrigues. Lisboa: Edições 70, 2002c.

HABERMAS, Jürgen. Comentários à ética do discurso. Trad. Gilda Encarnação. Lisboa: Instituto Piaget, 1999.

HABERMAS, Jürgen. On the Pragmatics of Communication. Edited by Maeve Cook. Cambridge, MA: The MIT Press, 1998. 
HABERMAS, Jürgen. Direito e Democracia: entre facticidade e validade, v.2. Trad. Flávio B. Siebeneichler. Rio de Janeiro: Tempo Brasileiro, 1997.

HABERMAS, Jürgen. Pensamento pós-metafísico: estudos filosóficos. Trad. Flávio Beno Siebeneichler. Rio de Janeiro: Tempo Brasileiro, 1990.

HEGEL, G. W. F. Linhas fundamentais da filosofia do direito, ou direito natural e ciência do Estado em compêndio. Trad. Paulo Meneses [et al.]. São Leopoldo, RS: Ed. UNISINOS, 2010.

HONNETH, Axel. The fabric of justice: On the limits of proceduralism. In: Justice and Recognition: On Axel Honneth and Critical Theory. Edited by: Nythamar Oliveira (et al.). PUCRS / Porto Alegre, Institute of Philosophy / Prague, 2015, p. 155-180.

HORKHEIMER, Max. Crítica de la razón instrumental. $2^{\underline{a}}$ ed. Trad. H. A. Murena; D. J. Volgemann. Buenos Aires: SUR, 1973.

McCARTHY, Thomas. "Reflections on Rationalization in the Theory of Communicative Action". In: Habermas and Modernity. Edited by Richard Bernstein. Cambridge, MA: The MIT Press, 1985a, p. 176-191.

McCARTHY, Thomas. The Critical Theory of Jürgen Habermas. Cambridge, MA: The MIT Press, 1985b.

MARCUSE, Herbert. One-Dimensional Man: Studies in the Ideology of advanced Industrial Society. New York: Routledge Classics, 1991.

NEVES, Marcelo. "Do consenso ao dissenso: o Estado democrático de direito a partir e além de Habermas". In: SOUZA, Jessé (Org.). Democracia hoje: novos desafios para a teoria democrática contemporânea. Brasília: Editora da UNB, 2001, p. 111-164.

SCHWEPPENHÄUSER, G. „Die ,kommunikative verflüssigte Moral': zur Diskursethik bei Habermas“. In: Unkritische Theorie: Gegen Habermas. Hrsg. Von Gerhard Bolte. Lüneburg: zu Klampen, 1989, p. 122- 145.

SEARLE, John. Os atos de fala: um ensaio de filosofia da linguagem. Trad. Carlos Vogt et al. Coimbra: Livraria Almedina, 1981.

SELL, Martin. "The Two Meanings of 'Communicative' Rationality: Remarks on Habermas's Critique of a Plural Concept of Reason". In: Communicative Action: essays on Jürgen Habermas's Theory of communicative action. Edited by Axel Honneth and Hans Joas: transl. by Jeremy Gaines and Doris L. Jones. Cambridge: MA: The Mit Press, 1991, p. 36-48.

WARNKEN, Georgia. "Communicative Rationality and Cultural Values". In: The Cambridge Companion to Habermas. Edited by Stephen White. Cambridge: MA: Cambridge University Press, 1995, p. 120-142.

WEBER, Max. Economía e sociedad: esbozo de sociología comprensiva. Trad. José Medina Echavarría (et al.). México: Fondo de Cultura Económica, 1944.

WEBER, Max. Conceitos básicos de sociologia. Trad. Rubens E. F. Frias; Gerard G. Delaunay. São Paulo: Centauro, 2002. 